May 2016

"Does the Provision of Information on their Skills Affect Students' Enrollment Choices?"

\author{
Nina Hestermann, Nicolas Pistolesi
}




\title{
Does the Provision of Information on their Skills Affect Students' Enrollment Choices?
}

\author{
Nina Hestermann ${ }^{1}$, Nicolas Pistolesi ${ }^{2}$
}

May 18, 2016

\begin{abstract}
This study assesses the impact of a French educational policy reform aimed at improving the match between students and their chosen field of study at university. As part of this reform, upon applying for entry to an undergraduate degree course, students are informed about their likelhood of succeeding given their observed skills. To examine the effect of the feedback they receive on students' choices, we compare students applying to different departments within the same university, some implementing the policy, providing candidates with feedback, whereas others do not. We find among those receiving a negative feedback that the proportion of students who decide to register for the degree course in question is reduced by about 7 percentage points but marginally significant at 10 percent level. Effects are heterogeneous according to students' origin and the type of high school they attended.
\end{abstract}

JEL Codes: H52, I23, I28

Keyworks: Access to Higher Education, Study Counseling.

Mots Clef: Accès à l’enseignement supérieur, Orienation scolaire.

1 Toulouse School of Economics, Université Toulouse 1 Capitole, nina.hestermann@gmail.com

2 Toulouse School of Economics, Université Toulouse 1 Capitole, nicolas.pistolesi@ut-capitole.fr. Address: 21, allée de Brienne 31015 Toulouse Cedex 06. Tel: (33) 5.67.73.27.89. We thank the institution providing us the data used in the paper and participants at the conference Public Policies Evaluation 2015 (Paris). All errors remain ours. 


\section{Introduction}

In 2014, 470.000 high-school graduates started their post-secondary education in France. This corresponds to roughly $60 \%$ of a cohort obtaining access to higher education, a higher proportion than ever before. Demand for certain degree courses, as such Health Care or Law, has risen spectacularly over the past ten years, with an increase of $30 \%$ and $18 \%$ respectively of registered first year students (MSER, 2015). Providing adequate conditions to enable such a large number of entrants to succeed in their studies represents a major challenge for the French education system. This problem is accentuated by the fact that these students come from diverse educational backgrounds. Additionally, French universities are not allowed to impose entry requirements and students are free to choose their field of study. This results in very heterogeneous skills for students entering the higher education system (OECD, 2010).

Faced with this situation, the French government adopted a certain number of policies to increase the proportion of students completing their undergraduate studies successfully. ${ }^{3}$ Some of the main measures put in place intervene early, before students even enter university. From the moment students indicate their desired course of study, the aim is to assist them in their choices, and guide them towards the degree best suited to their educational background and individual abilities. It is crucial to offer advice at this early point in students' higher education careers, as many seek to enter degree courses they are ill prepared for, paving the way to low performance, discouragement, and subsequent drop-out. A majority of those failing the final examinations of their freshman year (about $50 \%$ of each entering cohort), is likely do so due to a mismatch between course requirements and their skills (Gury, 2007).

3 The «Plan Réussite en Licence» (2008-2012) is the most famous example. 
The so-called «Active Orientation» policy, henceforth AO, aims to improve this match between students and their chosen degree courses. Put in place in 2009, it informs students about their chances of success in the degree courses they have declared their intention to apply to during their last year of high-school. Universities are free to choose in which way they convey this information to students. Most of them elect to give those students expressing interest in enrolling individual written feedback on the quality of the match to their chosen degree course, given their grades and the motivation letter they addressed to the university. As these recommendations are not binding, it is important for universities and policy makers to assess whether prospective students do indeed take into account the information they are given when deciding where to enroll. This is particularly salient in the case of the students who are weakest academically and thus incur the highest risk of failure in their freshman year.

So far, a study evaluating the effectiveness of this policy by assessing how students adjust their choices upon receiving such feedback has to our knowledge not been carried out.X In this article, we thus examine the effect of recommendations emitted by the university on students' enrollment decisions. We focus on students receiving negative feedback encouraging them to reconsider their choices. ${ }^{4}$ These students are at risk of not being able to cope with the requirements of the degree they intend to enroll for, notably because they lack the necessary skills in mathematics and abstract reasoning. We do indeed find an impact of the university expressing its reservations regarding students' enrollment, cautioning that their skills may not be sufficient to ensure successful completion of the degree: receiving such feedback reduces the proportion of students enrolling for the degree course concerned by 7 percentage points. This effect varies in size among the degree courses concerned and is not always significant at

4 This represents the least favorable feedback out of three types of recommendations emitted: the other two indicating a «neutral» or a «positive» message. 
the ten percent level. This indicates that the academically weakest applicants, who may also be the least well informed about course requirements, do indeed reconsider their choices when advised against enrolling, such that the AO policy does indeed seem to help attenuate mismatches between students and degree courses.

Many recent studies show the importance of incomplete information in human capital investment decisions, both regarding the perceived payoff to different educational choices, and regarding students' perception of their own abilities. Some also testify of the possibility to improve choices by providing additional information. As an example, Jensen (2010) studies eigth graders from the Dominican Republic. He documents students' misperception of the returns to education. In his sample, pupils largely underestimate returns, and those randomly assigned to receive complementary information about the true payoffs are found to complete more years of education as a result. In the United States, Stinebrickner and Stinebrickner (2014) elicit freshmen's beliefs about own academic ability and about the payoff to the degree course they are enrolled in. Following the cohort over time, they observe how these beliefs evolve and how they affect students' choices. For their sample, they find that drop-out rates can be explained by the evolution of individuals' beliefs in these two domains. ${ }^{5}$ Echoeing this, on a French sample, Beaupère and Boudesseul (2009) describe the very patchy knowledge students who fail their first year of university have of the requirements of the university system, suggesting that here, too, additional information might have improved choices.

In this article, we take advantage of a natural experiment to measure the causal effect of the

5 Avery and Kane (2004) and Hastings et al. (2015) also document the lack of information of high school students on higher education. 
recommendations sent to prospective students on their enrollment choices for their first year at university. The data we use stem from several departments of a large French university, one of which, from a certain point in time onwards, elects to give all students indicating the desire to enroll the type of feedback described above, while others do not provide such feedback to their prospective students. We compare enrollment rates between the treated students, i.e. those applying to the department providing feedback after a certain point in time, to untreated students: those applying to the same department, but before the implementation of the feedback policy, as well as those applying to different departments, in order to obtain an estimate of the causal effect of the feedback policy.

We thus contribute to the literature evaluating the effect of the provision of additional information to students or their parents on the former's educational careers. In the context of a US public school choice plan, Hastings and Weinstein (2008) examine whether providing supplementary information helps parents from disadvantaged backgrounds to pick good schools for their children, where school quality is defined by the proportion of students successfully graduating. Both the natural experiment and the field experiment whose data they exploit confirm that obtaining such information indeed orients parents towards better schools, and that attaining a school of better quality improves pupils' academic achievement. Avery (2010) carries out a field experiment to measure the impact of college counselling on highachieving students from low-income backgrounds. Though many students did not attend all the counselling sessions the intervention offered, he finds that students' choices are affected, notably regarding their propensity to apply to more competitive colleges. Bettinger et al. (2012) implement a field experiment to evaluate whether students from disadvantaged backgrounds benefit from receiving assistance in applying for financial aid for college 
attendance. They find that the treatment group exhibits higher college attendance and persistence rates. Remarkably, benefits even trickle down a generation : among the children of the original treated participants they find that two year college completion rates increase by 8 percentage points, from $28 \%$ to $36 \%$. Oreopoulos and Dunn (2013) provide information about the benefits of post-secondary education to high-school students, and as a consequence observe the treated to expect higher returns and also a higher educational attainment for themselves, as opposed to a control group who did not receive the information. In France, a randomized field experiment run by Goux, Gurgand and Maurin (2014) informs lowachieving students about high-school options which are adapted to their abilities. The group of students whose aspirations thus became more realistic, and who as a consequence chose the programs they were most suited for, were found to show a significant reduction in grade repetition and high-school drop-out. Other studies examine the effect feedback about past performance has on future educational attainment. Azmat and Iriberri (2010) carry out a field experiment in secondary schools. Compared to the control group, the treatment group receiving such information saw grades improve by about $5 \%$. Of the numerous and diverse studies examining different angles of the impact of imperfect information on educational attainment, and the capacity of interventions to improve outcomes, a majority find a significant effect both on choices and on subsequent performance of providing additional information to students and their families.

With respect to this literature, our paper's contribution is twofold: Firstly, the information transmitted to the students in our study concerns their competence relative to the requirements of the degree course they consider applying to. Such information is highly relevant in the French context where drop-out rates after the first year of undergraduate studies are extremely 
high. Secondly, the target population of the specific intervention we analyze are lowperforming high-school students whose risk of failing their first year is particularly large. Measuring the discouraging effect an unfavorable feedback has on their enrollment rates is particularly salient for informing policies seeking to reduce drop-out rates and better match students to their chosen programs of study. The following section describes the functioning of the feedback policy.

\section{Active Orientation and University enrollment decisions}

\section{Context}

The AO policy was voted by the French Parliament on August 10th 2007 as part of the law n²007-1199 on the «Independence and Responsability of Universities», commonly called LRU law. The article L123-3 of this law describes the AO policy as an important task of the public service of education. Higher education institutions, notably universities, are called upon to inform applicants about how well their desired course of study matches their educational background. The objective of this procedure is to prevent students embarking on degree courses they are not suited for, thus paving the way for future difficulties and contributing to the high drop-out rate after the first year of higher education.

Universities convey their feedback to students through a web-based platform called Post-Bac. Since 2009, each January, high-school students in their final year register on the Post-Bac site to compile a list of degree courses and higher education institutions they intend to apply to for entry in the fall term. They are allowed to list up to 24 combinations of degrees and institutions, ranked by order of their preference. Higher education institutions then receive lists of all candidates having expressed an intention to enter one of their degree courses; this 
list equally contains detailed information on the students' previous education, such as the type of high-school they went to, the grades they received during their last two years of highschool, or the optional courses they chose.

Each department within a university is free to decide upon the criteria it deems most relevant to judge whether a student's skills correspond to the requirements of the degree course she intends to enroll in. The feedback students receive consists in one of three types of messages, which we will designate as «positive», «neutral», or «negative» regarding the student's intended choices. ${ }^{6}$ From mid-April onwards, candidates have access to these messages when logging in to the Post-Bac website. They can then elect to maintain or modify their choices, taking into account the feedback they received. In July, after passing their high-school final exam, those graduating are either assigned to the non-selective degree course that tops their list of choices, or else, to the first selective one that accepts them.

In this study, we focus on a single French university that consists of three main departments, Law, Economics and Business Administration and Communication. ${ }^{7}$ These departments differ in the way they provide students with feedback of the kind described above. One of them, we will call it experimental department, provides feedback to all applicants, sending an evaluation to all students expressing an interest to register in one of its degree courses. The other two departments, which we will call control departments, send feedback only to those candidates who ask for it. Under this latter system, only very few students ask for feedback; in total, around $4 \%$ do so in both control departments taken together over the period from 2008-2013. This represents 1736 prospective students in those departments. Moreover,

6 The exact message is provided in Appendix.

7 There is as well a department of Computer Sciences in this institution, but we excluded it because of its much smaller size. 
candidates in the treatment department receive feedback based on their grades in mathematics during their last year of high-school, whereas the control departments evaluate students based on the major in high-school. Although in the treament department no strict cut-off exists for evaluating students regarding their grade in mathematics, we observe that the probability of receiving a negative feedback increases sharply as students' grade in mathematics in highschool falls below 10 points out of 20. Similarly, we observe a sharp increase in the probability of receiving a positive feedback for students whose grades in mathematics are above 12 points. For students with grades between 10 and 12 the probability of receiving a neutral feedback is thus very high. The faculty staff deciding on the recommendations are indeed advised to use as a principal criterion students' grades in mathematics, but it is at their discretion to also base their decision on additional information on each student they obtain through the Post-Bac site, such as the average grade in the student's class, the motivation letter, or the reputation of the high-school the student attended. ${ }^{8}$ For the present study, we use an identification strategy based on comparing the proportion of students enrolling among different departments. The AO policy started in 2009, which leaves us with one year of data before the reform, covering the applicants of the 2008 cohort. These applicants did not receive any feedback no matter their chosen degree course.

\section{Does negative feedback lead students to change their field of study?}

The treatment we focus on consists in reception of a negative feedback, as opposed to a neutral one. We examine the impact this has on the choice of degree course students register for in their first year at university. We use the students applying to degree courses proposed by

\footnotetext{
8 In a companion paper, Pistolesi (2016) uses the discontinuity between the numerical score in mathematics in high school and the probability to enroll to assess the causal impact of the feedback.
} 
departments who do not issue such feedback as control groups. To reinforce the validity of our study, additional control groups are constituted by students applying to each of these departments and having obtained a grade in mathematics between 10 and 12 points. We thus measure the effect of receiving a negative feedback as opposed to a neutral one for treated candidates (ie those applying to the experimental department and with grades in mathematics below 10), compared to the non-treated candidates (ie those applying to the control department, or disposing of a grade between 10 and 12), and this during the period when the feedback policy was in place, compared to the year before that. This triple difference method is explained in more detail in the following section.

\section{Data and Identification Strategy}

The aim of this study is to assess the causal effect receiving negative feedback has on students' decision to register in a given degree course at entry into university. This feedback is given to a specific group among them, those having obtained less than 10 points in mathematics in high-school, we call these the treatment group. To measure this effect we need to control for any systematic shock affecting the entry to the experimental degree courses correlated with the implementation of the AO policy. To neutralize any shock affecting enrollment to any degree course at a given point in time, we include time dummies for each period. We also include dummies for each type of degree course to account for permanent differences between the mean characteristics of the applicants. Finally, we include degree-byyear dummies to control for any shock specific to each course that is correlated with the start of the AO policy. To sum up, we compare candidates receiving negative feedback in the

experimental degree courses to individuals in the same degree courses but who receive different feedback, and we measure the relative change in the decision to register with respect 
to candidates in degree courses that did not implement this feedback policy.

This identification strategy mirrors closely, and extends, the difference-in-differences approach. ${ }^{9}$ The latter method consists in comparing the evolution over time of a treatment group, affected by the reform, to that of a control group not touched by it. However, our method has the advantage of requiring weaker assumptions than the latter, which suits our objective. In particular, it does not necessitate, contrary to the double-difference strategy, that the time trend of the explained variable be parallel for the treatment group and for the control group, since we use a third degree of comparison within both groups, between those having negative feedback and those who do not, allowing different temporal changes between the treatment and the control groups. Our difference-in-difference-in-difference (DDD) estimator only requires that there be no shock affecting simultaneously the relative choices of the treatment group in the same degree course and the same year as the start of the AO policy.

These weaker assumptions are crucial for our pupose, as clearly in our case it would not be credible to regard students scoring below 10 points in mathematics and listing a nonexperimental department as a control group not affected by the reform. Indeed, as students are allowed to list multiple options even within the same university among the degree courses they consider desirable options for themselves, it is natural that the non-experimental departements will also be affected by this reform: Students having received a negative feedback when requesting entry into a degree course dispensed by the experimental departement and who are deterred by this information, are likely to turn not only to other universities, but to different degree courses within the same university. This is all the more likely as the information they receive through the feedback pertains to their lack of

9 Gruber (1994) is the first study introducing the DDD estimator in a very different context. 
mathematical skills, which would endanger their success in any degree course requiring such skills, be it at this university or another. Thus, it is natural that these students should turn towards degrees requiring less mathematical knowledge and abstract thinking, within the same university. Similarly, students scoring above 10 out of 20 points cannot be regarded as unaffected by the reform either, as they, too, receive new information after the policy is implemented which may affect their decision : Not receiving negative feedback, and thus indirectly receiving approval regarding their planned course of study, may indeed confirm them in their choice and increase their enrollment rate, just as receiving negative feedback may lower the propensity to enroll for those who receive it. Thus, we will use the terminology of treatment versus control, and experimental versus non-experimental groups to facilitate the description and distinction of the various groups of students concerned, who are either directly or only indirectly affected by the policy.

We therefore stress here that what we aim to measure is the relative change in enrollment rates between low- and higher-achieving students (the former likely to receive negative feedback, the latter not) within the department issueing such feedback (the experimental one), compared to the relative change in enrollment between these two groups of students in departments not issueing feedback (the non-experimental ones). This overall change in relative propensity to enroll constitutes our parameter of interest, and it is composed of changes in enrollment rates induced in various subgroups, as outlined above : (1) those directly affected by the feedback, as regarding their enrollment in the degree they received feedback for, (2) those same students, but regarding their choice to enroll in another department, (3) students receiving neutral as opposed to negative feedback, who may find themselves encouraged to pursue their desired option.

A triple difference estimation captures this relative change, composed of changes in various 
subgroups of students, and allows to derive a causal interpretation of the policy we examine under the very weak assumption mentioned above: that there be no other shock affecting these relative enrollment rates and coinciding with the moment of implementaion of the AO policy.

In order to implement this method, we use administrative data of a French university, covering the years 2008-2013. To do so, we merge two databases: the first is based on information retrieved through the Post-Bac website. It collects details for students whose list of desired degree courses included one of those proposed by the university. These data include socio-demographics, such as age, gender, place of living or nationality, but also a detailed account of the grades obtained in high-school, the name and location of the school, as well as a national student identification number. The Post-Bac data also contain information on the degree courses each student considers registering in, and on the kind of feedback they received as part of the AO policy whose impact we seek to evaluate. The second source of data we use stems from the administrative services of the university itself. It records the name and national identification number of all students enrolled at the university, as well as the degree course they are actually enrolled in. Unfortunately, we do not have access to the grades the students obtained once enrolled at university. Each year, around 10.000 senior highschool students list at least one of the degree courses the university proposes as a desired option. Around 3.000 of them then decide to enroll at the university each fall. 
Figure 1: Enrollment Rates by Year and Treatment Status
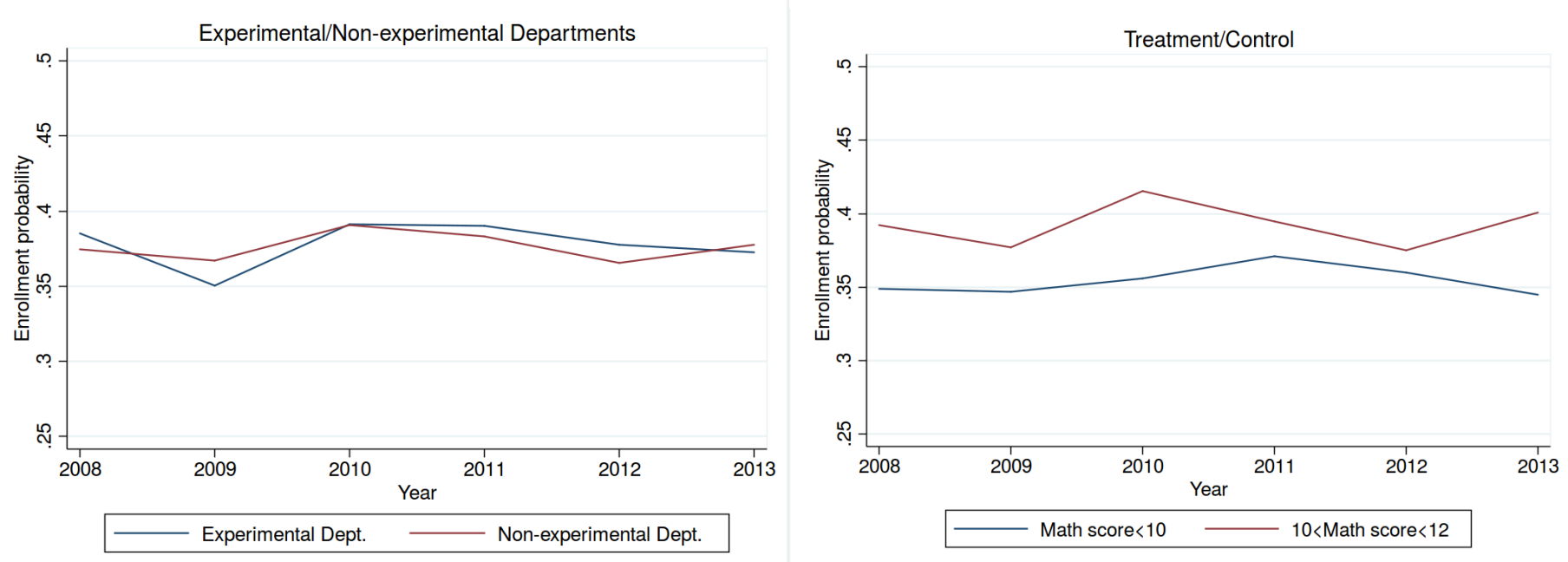

Notes: The graph on the left hand side shows the yearly enrollment rates separately for the experimental and non-experimental departments. The graph on the right hand side displays yearly enrollment rates separately for treated and control groups (Mathematics grade lower than 10/20 or between 10 and 12/20, respectively).

Figure 1 presents the change over time in the enrollment rate between 2008 and 2013 for several groups of students. The left panel compares the proportion of applicants that register in the experimental department, providing feedback to any first year applicant, with the nonexperimental departments that do not provide feedback. The right panel displays the probability to register in the experimental department for those with mathematics grades below 10, and for those with grades between 10 and 12. In both panels we do not observe any different change over time. If the time trend was different in any of the panels, it would not invalidate the hypothesis of our approach. As we use a triple difference approach, the parallel trend assumption is not necessary, as explained above.

A drawback of these data that needs to be kept in mind is that they do not provide information on the enrollment decisions of students who do not end up enrolling in one of the degree courses proposed by the university. We thus cannot tell whether students who decide not to 
enroll at this university go on enrolling at a selective course of study outside the university system (such as a «classe prépa», or IUT), whether they enroll for a non-selective degree course at another university, or else decide not to pursue post-secondary studies at all. This is an important drawback, but it seems likely that its implications are limited if we recall the type of students on whom we study the impact of receiving negative feedback: this almost exclusively concerns those who obtain less than 10 out of 20 points in mathematics at highschool. They are thus unlikely to be accepted for entry to selective degree courses. The option of renouncing from further studies altogether does not seem to be of major relevance either: national aggregate statistics show that almost all students having obtained high-school diploma pursue post-secondary studies (MSER, 2015). Consequently, based on these facts, we can safely assume that most students reconsidering their choice due to unfavorable feedback will end up enrolling for a non-selective degree within the university system which poses weaker requirements on their skills in mathematics.

Our database initially contains information on 61.086 senior high-school students over the period from 2008 to 2013 . We firstly eliminate from these data individuals who do not pass their final year of high-school in mainland France. Secondly, we only keep students having a grade of no more than 12 out of 20 points in mathematics in the first semester of their final year of high-school. Of those remaining, we keep those for whom none of the relevant variables is missing. This reduces our sample by 8.414 observations based on the first criterion, by 20.062 observations based on the second one, and by 442 observations due to missing variables. Our remaining sample thus yields information on the desired options listed, the type of feedback received (if any), and the enrollment choices of 31.168 senior highschool students between 2008 and 2013. Table 1 contains descriptive statistics based on our final sample. 
Table 1 : Descriptive Statistics

\begin{tabular}{|c|c|c|c|c|c|c|c|c|}
\hline \multirow{4}{*}{ Enrollment (\%) } & \multicolumn{4}{|c|}{ Grade in Mathematics $<10 / 20$} & \multicolumn{4}{|c|}{ Grade in Mathematics $>10$ and $<12 / 20$} \\
\hline & \multicolumn{2}{|c|}{ Non-Experimental Dept } & \multicolumn{2}{|c|}{ Experimental Dept } & \multicolumn{2}{|c|}{ Non-Experimental Dept } & \multicolumn{2}{|c|}{ Experimental Dept } \\
\hline & Before AO & After AO & Before AO & After AO & Before AO & After AO & Before $\mathrm{AO}$ & After AO \\
\hline & 0.33 & 0.35 & 0.4 & 0.36 & 0.4 & 0.4 & 0.38 & 0.38 \\
\hline & 0.47 & 0.48 & 0.49 & 0.48 & 0.49 & 0.49 & 0.49 & 0.49 \\
\hline Negative Feedback (\%) & 0 & 0 & 0 & 0.87 & 0 & 0 & 0 & 0.33 \\
\hline & 0 & 0 & 0 & 0.34 & 0 & 0 & 0 & 0.47 \\
\hline Age & 19.05 & 19.03 & 18.94 & 19.02 & 18.92 & 18.78 & 18.84 & 18.71 \\
\hline Male (\%) & $\begin{array}{l}1.01 \\
0.45\end{array}$ & $\begin{array}{l}1.09 \\
0.44\end{array}$ & $\begin{array}{l}1.01 \\
0.64\end{array}$ & $\begin{array}{l}1.08 \\
0.67\end{array}$ & $\begin{array}{l}1.03 \\
0.41\end{array}$ & $\begin{array}{l}1.03 \\
0.38\end{array}$ & $\begin{array}{l}1.14 \\
0.65\end{array}$ & $\begin{array}{l}0.99 \\
0.58\end{array}$ \\
\hline French Nationality (\%) & $\begin{array}{c}0.5 \\
0.92\end{array}$ & $\begin{array}{c}0.5 \\
0.93\end{array}$ & $\begin{array}{l}0.48 \\
0.91\end{array}$ & $\begin{array}{c}0.47 \\
0.91\end{array}$ & $\begin{array}{c}0.49 \\
0.93\end{array}$ & $\begin{array}{l}0.49 \\
0.94\end{array}$ & $\begin{array}{l}0.48 \\
0.92\end{array}$ & $\begin{array}{l}0.49 \\
0.93\end{array}$ \\
\hline Needs-based scholarship (\%) & $\begin{array}{c}0.27 \\
0.28\end{array}$ & $\begin{array}{l}0.26 \\
0.25\end{array}$ & $\begin{array}{c}0.29 \\
0.23\end{array}$ & $\begin{array}{l}0.29 \\
0.21\end{array}$ & $\begin{array}{l}0.25 \\
0.22\end{array}$ & $\begin{array}{c}0.24 \\
0.22\end{array}$ & $\begin{array}{l}0.28 \\
0.19\end{array}$ & $\begin{array}{l}0.25 \\
0.17\end{array}$ \\
\hline General High School (\%) & $\begin{array}{l}0.45 \\
0.94\end{array}$ & $\begin{array}{l}0.43 \\
0.9\end{array}$ & $\begin{array}{l}0.42 \\
0.97\end{array}$ & $\begin{array}{l}0.41 \\
0.9\end{array}$ & $\begin{array}{l}0.42 \\
0.92\end{array}$ & $\begin{array}{l}0.42 \\
0.89\end{array}$ & $\begin{array}{c}0.4 \\
0.93\end{array}$ & $\begin{array}{l}0.37 \\
0.91\end{array}$ \\
\hline Public High School (\%) & $\begin{array}{c}0.24 \\
0.81\end{array}$ & $\begin{array}{c}0.29 \\
0.78\end{array}$ & $\begin{array}{l}0.16 \\
0.81\end{array}$ & $\begin{array}{c}0.3 \\
0.76\end{array}$ & $\begin{array}{c}0.27 \\
0.77\end{array}$ & $\begin{array}{c}0.31 \\
0.74\end{array}$ & $\begin{array}{c}0.25 \\
0.78\end{array}$ & $\begin{array}{l}0.29 \\
0.74\end{array}$ \\
\hline Distance to University (\%) & $\begin{array}{c}0.39 \\
0.12\end{array}$ & $\begin{array}{c}0.42 \\
0.15\end{array}$ & $\begin{array}{c}0.36 \\
0.14\end{array}$ & $\begin{array}{l}0.43 \\
0.16\end{array}$ & $\begin{array}{c}0.42 \\
0.13\end{array}$ & $\begin{array}{c}0.44 \\
0.16\end{array}$ & $\begin{array}{c}0.41 \\
0.13\end{array}$ & $\begin{array}{c}0.44 \\
0.16\end{array}$ \\
\hline Observations & $\begin{array}{l}0.19 \\
558 \\
\end{array}$ & $\begin{array}{c}0.23 \\
9363\end{array}$ & $\begin{array}{l}0.23 \\
222 \\
\end{array}$ & $\begin{array}{c}0.25 \\
3129\end{array}$ & $\begin{array}{c}0.2 \\
1086\end{array}$ & $\begin{array}{c}0.23 \\
11591 \\
\end{array}$ & $\begin{array}{l}0.21 \\
484 \\
\end{array}$ & $\begin{array}{c}0.23 \\
4735\end{array}$ \\
\hline
\end{tabular}

Notes: The table indicates the average characteristics of the sample, along with standard deviations. Columns 1, 2, 5 and 6 describe candidates in nonexperimental departments, columns 3, 4, 7 and 8 candidates in the experimental department. AO stands for Active Orientation Policy.

The left hand side panel displays figures for the students whose high-school grades in mathematics fall below 10 points, the right hand side panel covers those whose grades fall between 10 and 12 points. Within each panel, the different columns distinguishe between the experimental department, that is, the one giving feedback to all students, and the control departments, which do not give such systematic feedback. Furthermore, within each of these groups, we distinguish between the period before and those after implementation of the AO policy.

Table 1 shows that the proportion of students receiving unfavorable feedback is much higher among those whose grades fall below 10/20 in mathematics than for their peers scoring between 10 and 12 points: 87\% relative to 33\%, respectively. Students listing the experimental department among their options are somewhat more likely to be male than those 
listing the non-experimental ones (65\% as opposed to 45\%). Otherwise, candidates in the two types of departments are comparable in all major characteristics: in terms of age, likelihood to enroll, nationality, socio-economic status of their parents (as measured by receiving financial aid during high-school), whether they attend a general or a vocational high-school, whether it is a public or private school, and in terms of the distance of this school to the university. We observe some evolution over time in the composition of the different groups: Among those listing options from the experimental department, the proportion of students having attended a general high-school diminishes from $97 \%$ to $90 \%$, and the proportion of male students decreases from $65 \%$ to $58 \%$ among the group scoring between 10 and 12 points in mathematics. In the regressions we use in the analysis we control for these variables in order to obtain an effect that does not depend on these changes.

\section{The effect of negative feedback on enrollment}

Table 2 illustrates the method of estimation in triple differences of the impact of negative feedback on students' enrollment decisions. Panel A compares the change in the enrollment rate for candidates in the experimental department who have a grade of less than 10 points in mathematics to the enrollment rate for those who equally have a grade of less than 10 points but are candidates in the non-experimental department. Each cell indicates the proportion of students who enrolled, as well as the standard error of this proportion. After AO has started we observe a drop of 3,4 percentage points in the enrollment rate in the experimental department for this group of students. For non-experimental departments, those not giving systematic feedback to all students, we observe on the contrary an increase of 2.3 percentage points between the pre-implementation period in 2008, and the post-implementation period of 2009-2013, on the other hand. Overall, for students with grades in mathematics below 10 
points, we thus observe a relative change of -5.7 percentage points in enrollment in the experimental relative to the non-experimental departments from 2009 onwards. To put this effect into perspective, 35\% of students enroll in non-experimental degree courses, as shown in Table 1; the effect is thus sizeable. However, if there were shocks affecting only enrollment in the experimental department, or vice versa, at the same time period as the date of implementation of the AO policy, this difference-in-differences estimate would not be a correct measure of the causal effect of the policy. In panel B of Table 2 we therefore carry out the same exercise, again on candidates for both types of departments, but this time on those whose grades in mathematics fall between 10 and 12 points. They are suitable to serve as control groups as they are highly unlikely to receive a negative feedback. For this group, we find that under $\mathrm{AO}$, the enrollment rate in degrees proposed by the experimental department increases by 0.6 percentage points relative to enrollment in degrees in the non-experimental departements. This increase is not significant at the standard thresholds though. We obtain our triple-difference estimate if we now take the difference between the values obtained in each of the two panels. The result is displayed at the bottom of the Table. We find that with respect to the time period before the AO policy, the enrollment rate afterwards is 6.2 percentage points lower for students whose high-school grade in mathematics is below 10 points, and who are candidates for a degree in the experimental department applying the feedback policy, compared to students in the same department whose grade in mathematics lies between 10 and 12 points, and to students in the other departements. However this effect is not significant at the $10 \%$ level. 
Table 2: Triple difference estimates of the negative feedback on enrollment decisions

\begin{tabular}{|c|c|c|c|}
\hline & Before start of $\mathrm{AO}$ & After start of AO & $\begin{array}{c}\text { Difference } \\
\text { btw. periods }\end{array}$ \\
\hline A Treatment group : Candidates with gra & n 10 points out of 20 & in mathematics & \\
\hline Experimental Department & 0.396 & 0.363 & -0.034 \\
\hline & & & 0.034 \\
\hline Non-Experimental Department & 0.33 & 0.353 & 0.023 \\
\hline & & & 0.021 \\
\hline Difference between departments & 0.067 & 0.01 & \\
\hline Difference in Differences & -0. & & \\
\hline & 0 . & & \\
\hline B. Control group : Candidates with grade & and 12 points in mat & ematics & \\
\hline Experimental Department & 0.38 & 0.384 & 0.004 \\
\hline & & & 0.023 \\
\hline Non-Experimental Department & 0.398 & 0.396 & -0.002 \\
\hline & & & 0.016 \\
\hline Difference between departments & -0.018 & -0.012 & \\
\hline Difference in Differences & 0.0 & & \\
\hline & $0 . c^{2}$ & & \\
\hline Difference-in-Difference-in-Difference & -0. & & \\
\hline & & & \\
\hline
\end{tabular}

Notes: The table shows the enrollment probabilities for first year of studies for different groups of students, along with the corresponding standard deviations. The first column describes these probabilities in 2008, the second column between 2009 and 2013.

The above triple differences estimator amounts to a mere comparison of mean enrollment rates between different groups. To obtain more precise estimates of this effect, we use a linear regression analysis. Controlling for observed heterogeneity, the regression estimates reduce the standard error of the coefficients. The estimating equation we use is the following one: 


$$
y_{i j t}=\alpha+\beta_{1} X_{i j}+\beta_{2} \tau_{t}+\beta_{3} \delta_{j}+\beta_{4} F_{i}+\beta_{5}\left(\delta_{j} \times \tau_{t}\right)+\beta_{6}\left(\tau_{t} \times F_{i}\right)+\beta_{7}\left(\delta_{j} \times F_{i}\right)+\beta_{8}\left(\delta_{j} \times \tau_{t} \times F_{i}\right)+\epsilon_{i j t .}(1)
$$

where $i$ indicates individuals, $j$ indicates degree courses (with 1 denoting degrees dispensed by the experimental department, and 0 all others) and $t$ denotes time periods (taking the value 1 for periods after implementation of the policy, and 0 otherwise). $y_{i j t}$ represents the decision to enroll at university (taking the value 1 if the student enrolls, 0 otherwise), $\mathbf{X}_{\mathrm{ij}}$ is a vector of observed individual characteristics and of those of the high-school attended, $\delta_{j}$ is a department fixed effect, $\tau_{t}$ a fixed effect for each time period, and $F$ a dummy variable for students whose high-school grade in mathematics is below 10 points. The coefficient of interest is $\beta_{8}$. Just as the overall effect obtained in Table 2 and described above, it measures the change in the enrollment rate of the treated individuals from the date of implementation of the AO policy in the department applying the policy, compared to students having higher mathematics grades or who are enrolled in other departments. The control variables $\mathbf{X}_{\mathrm{ij}}$ include age, gender, nationality, (1 indicating French individuals, 0 all others), socio-economic status as measured by receiving financial aid in high-school, and finally indicators for taking additonnal optional courses during high-school. The characteristics describing the high-school attended include: an indicator for public versus private status, if it is a general or vocational high-school, the distance between the high-school and the university, as well as the squared distance. Finally, the pass-rate of the end of high-school exam (called baccalauréat) in log is used to measure differences in high-school quality. 
Table 3: Regression Analysis: Effect of Negative Feedback on Enrollment

\begin{tabular}{l|cccc|}
\hline \multicolumn{5}{c|}{ Dependent Variable : Share of Candidates Enrolled } \\
& 1 & 2 & 3 & 4 \\
\hline Negative Feedback & -0.062 & -0.073 & -0.076 & -0.075 \\
& $(0.048)$ & $(0.047)$ & $(0.047)$ & $(0.046)$ \\
Control Variables & $\mathrm{N}$ & $\mathrm{Y}$ & $\mathrm{Y}$ & \\
Year dummies & $\mathrm{N}$ & $\mathrm{N}$ & $\mathrm{Y}$ & $\mathrm{Y}$ \\
Departmental trends & $\mathrm{N}$ & $\mathrm{N}$ & $\mathrm{N}$ & $\mathrm{Y}$ \\
Observations & 31168 & 31168 & 31168 & 31168 \\
R Squared & 0,002 & 0.072 & 0.075 & 0.085 \\
\hline
\end{tabular}

Notes: Column 1: DDD regression without controls; Column 2: DDD regression with controls; Column 3: DDD regression with controls and dummies for each treatment year; Column 4: DDD regression with controls and year-departments dummies.

Results from estimations of equation (1) are displayed in Table 3; each column corresponds to a different specification. In the first column, no explanatory variables are added to the regression, so that we reproduce the result shown in Table 2: a treatment effect of 6.2 percentage points, significant at only $19.6 \%$. In column 2 we see that introducing the time invariant control variables $\mathbf{X}_{\mathrm{ij}}$ improves precision as we are able to explain a larger share of the variance: the estimated treatment effect is slightly larger in absolute value at -7.3 percentage points and significant at an $11 \%$ level. The third column shows the coefficients resulting from a specification replacing the indicator variable for the post-implementation periods by five indicators, one for each of the five post-implementation years included in our data, 2009 up to 2013. This captures yearly fluctuations in enrollment rates across all degree courses, and thus reduces the share of unexplained variance, such that the estimated coefficient of -7.6 percentage points is now significant at the $10 \%$ level. Finally, the fourth column displays results from an inclusion of period-by-department dummies, that is, 
interaction terms between the indicators for the experimental vs non-experimental departments, and a linear time effect (see Angrist et Pischke, 2008). We find a coefficient of -7.5 percentage points. It is almost identical in size to the previous specification. This indicates that results are robust to time varying shocks affecting experimental and nonexperimental departments differently. These results thus lead us to confirm the conclusion that those candidates receiving negative feedback are about 7 percentage points less likely to enroll than their peers receiving neutral feedback, a coefficient just significant at a $10 \%$ level in our regression specification.

Table 4 :Effect of negative feedback on enrollment for different treatment groups

\begin{tabular}{|c|c|c|c|c|c|}
\hline \multicolumn{6}{|c|}{ Dependent variable : Share of Candidates Enrolled } \\
\hline & 1 & 2 & 3 & 4 & 5 \\
\hline \multirow[t]{2}{*}{ Mathematics grade $<10 / 20$} & $-0,076$ & & & & \\
\hline & $(0,047)$ & & & & \\
\hline \multirow[t]{2}{*}{ Mathematics grade $>7$ and $<10 / 20$} & & $-0,062$ & & & \\
\hline & & $(0,047)$ & & & \\
\hline \multirow[t]{2}{*}{ Candidates for Z1 } & & & $-0,099$ & & \\
\hline & & & $(0,06)$ & & \\
\hline \multirow[t]{2}{*}{ Candidates for Z2 } & & & & $-0,074$ & \\
\hline & & & & $(0,075)$ & \\
\hline \multirow[t]{2}{*}{ Candidates for Z3 } & & & & & $-0,036$ \\
\hline & & & & & $(0,098)$ \\
\hline Control Variables & $\mathrm{Y}$ & $\mathrm{Y}$ & $\mathrm{Y}$ & Y & $\mathrm{Y}$ \\
\hline Observations & 31168 & 30833 & 24828 & 27256 & 24280 \\
\hline R-squared & 0,075 & 0,075 & 0,078 & 0,076 & 0,074 \\
\hline
\end{tabular}

Notes : The table shows the effect of negative feedback on the choice to enroll for different sub-groups of treated students. (1) Main specification. (2) Restricts group of treated students to those with grades in mathematics between 7 and 10/20, (3) restricts the sample to candidates for Z1 (4) restricts the sample to candidates for Z2 (5) restricts to candidates for Z3. Z1, Z2 and Z3 refer to different degree courses within the experimental department, as outlined in the main text. 
Table 4 shows the regressions corresponding to the specification used in column 3 of Table 3 (inclusion of time dummies for each period), but distinguishes between different treatment groups, all composed of candidates for entry into degree courses proposed by the experimental department, but differing in either their mathematics grades at high-school, or else in the degree course they enroll in among those offered by the department. The first column reproduces the results from Table 3 to allow for easy comparison. The second column of Table 4 restricts the sample of treated students to those whose grade in mathematics at high-school falls between 7 and 10 points out of 20; arguably a more homogeneous group that is also more similar to their peers in the control group. ${ }^{10}$ The estimated treatment effect decreases slighlty in absolute value, but is still close to that estimated before, at -6.2 percentage points.

Column 3 to column 5 of Table 4 divide the sample of individuals composing the treatment group according to the degree course dispensed by the experimental department that they listed. In the experimental department there are three degree courses that we will call Z1, Z2 and Z3. Z1 integrates elements of the humanities and therefore necessitates good French langage skills, both written and oral, Z3 is more technical with a heavy weight given to mathematics, and Z2 is in between the two previous degree courses in terms of skill requirements. These three different degree courses use the same feedback system and apply the same criteria according to which feedback is given. The third column of Table 4 restricts the treatment group to candidates for degree course Z1, the fourth column to candidates for Z3, and the fifth to those who are candidates for Z2. The estimated treatment effect of receiving negative feedback is close for candidates for Z1 and Z2, and a little higher in absolute value than the one obtained from estimation on the whole sample: -9.9 and -7.4

10 We tested the effect of imposing different restrictions on the lower bound for the mathematics grade, with similar results. 
percentage points, respectively. For candidates to Z3, we obtain an effect that is much smaller in absolute terms, -3.6 percentage points, and not significant. A possible interpretation of this difference observed for candidates for Z3 might be that these students already have a good knowledge of their own skills in mathematics, or believe they do, such that feedback affects their choices less.

Table 5 : Effect of Negative Feedback on Enrollment : Robustness Checks

\begin{tabular}{|lcccc|}
\hline \multicolumn{4}{|c|}{ Dependent Variable : Share of Candidates Enrolled } \\
& 1 & 2 & 3 & 4 \\
\hline Period 2009-2010 & -0.072 & & & \\
& $(0.048)$ & & & \\
Period 2011-2013 & & -0.068 & & \\
& & $(0.048)$ & & \\
Same Region as University & & & -0.109 & \\
& & & $0.058)$ & \\
General High School & & & & -0.064 \\
& & & & $0.053)$ \\
Control Variables & $\mathrm{Y}$ & $\mathrm{Y}$ & $\mathrm{Y}$ & $\mathrm{Y}$ \\
Observations & 14046 & 19472 & 21262 & 24741 \\
R-squared & 0.1 & 0.06 & 0.035 & 0.085 \\
\hline
\end{tabular}

Notes : The table shows the effect of negative feedback on enrollment for different sub-samples of the treated students. Column 1 restricts the treatment period to 2009-2010. Column 2 restricts to 2011-2013. Column 3 focuses on students living in the same region as the university. Column 4 includes only students attending a general high school.

Table 5 displays results from further robustness checks, which are obtained, firstly, by varying the time periods taken into account for the treatment period, so as to evaluate possible differences between short- and longer-term effects of the policy. Secondly, we also differenciate treatment groups by the region of residency of the students' parents, and by the 
type of high-school the students attend. By comparing results for these different sub-groups of the treated students, we assess whether the effect is homogeneous across the treated population of students.

The first column compares enrollment rates between the period before implementation of the AO policy, 2008, and the first two years it was in place, 2009 and 2010. The second column restricts the treatment period to the three remaining years in our data when the policy was in place, 2011 through 2013. Comparing the coefficients obtained from these two estimations allows to assess whether the medium term effect of the policy, as measured 3 to 5 years after implementation, differs from that observed during the first two years. We observe only the slightest difference between the coefficients: while the effect size during the first two years is -7.2 percentage points, it is -6.8 percentage points during the later three years. The precision of the estimates is lower, as we divided the sample and thus reduced its size: the estimated coefficients are only significant at the $13 \%$ and $16 \%$ levels, respectively.

The estimates displayed in the third column of Table 5 result from restricting our sample to students living in the same region as the university. They represent the majority of candidates. We find that the estimated coefficient is indeed larger in absolute value for students originating from the same region as the university: receiving a negative feedback as opposed to a neutral one reduces the probability of enrollment by 10.9 percentage points. This is likely due to the fact that students from other regions tend to list this university as one of their less desired options ; they try first to gain entry to a university closer to their home. Thus, they often decide not to register at this university in any case, independently of the feedback they receive. The effect of feedback for this group is thus weaker, and excluding them thereby increases the estimated coefficient's absolute value. 
Finally, column 4 lists results of a regression where the sample is constituted of students attending a general high-school, as opposed to a vocational one. These students are on average more likely to go on to study for higher education degrees which take longer to complete, such as the ones we examine here. We do not find any marked difference in effect size for these students however; the estimated drop in the likelihood to enroll is 6.4 percentage points.

\section{Discussion and Conclusion}

In this study, we examine whether the "Active Orientation" policy has an impact on the kind of degree course students decide to enroll in for their first year at university. Students whose skills in mathematics the university deems to be too low to successfully complete the degree course they intend to enroll in will more often modify their choice if informed of their low chances of success in their preferred subject. Among students having listed a degree course as a desired option, the enrollment probability diminishes by about 7 percentage points after implementation of the AO policy, under which feedback is provided to all students expressing the desire to enroll. This drop is a sizeable effect when compared to an average enrollment probability of 35 percent before implementation of the policy. We find this result to be robust across different specifications, notably regarding different definitions of who constitutes the treated group of students. The deterrence effect of receiving negative feedback is greater for students living in the same region as the university, and for those whose chosen specialization in high-school is less relevant to the subject of the degree course they intend to enroll in. 
However, it is important to qualify these findings, due to several factors. Firstly, the estimated coefficient is only marginally significant at the ten percent level. This is notably due to the fact that the data available only cover a single year of observations before implementation of the feedback policy, namely those students entering higher education institutions in the fall of 2008. To our knowledge, no data have been collected before 2008 since Post-Bac site was not existing. As a consequence, the sample size is reduced. The comparison of the periods before and after implementation of the policy is thus less precise than it would be were additional cohorts of students observed before 2008.

Finally, different approaches to assess the impact of this feedback policy may lead to sizeable differences in the estimated effect sizes. A companion study, Pistolesi (2016), uses the same data but relies on a different identification strategy. It takes advantage of the fact that there exists a threshold grade in mathematics below which university staff sending the feedback are expected to indicate their reservations regarding the students desired choice. This allows to apply a regression discontinuity design (Hahn, et al. 2001), comparing the decisions of students whose grades are situated just below the threshold to those with grades just above it. These two groups of students are arguably very similar, the only difference between them being that one group is highly likely to receive negative feedback. In this setting, using subsamples of students alike in everything but the feedback their receive, the marginal effect of the policy is found to be more pronounced than in the present study. The probability to enroll diminishes by about 14 percentage points for those receiving negative feedback compared to those whose feedback is neutral. This constitutes a sizeable difference between the results of the two studies. A regression discontinuity design is by definition focused on individuals situated just below and just above the cutoff value of the running variable, a much more restricted sample than the one studied here. Comparing the results of the two studies thus 
allows us to conclude that those individuals situated close to the threshold are the most sensitive to receiving negative feedback and the most likely to modify their decision as a consequence.

Extensions that should be explored in future work include a closer examination of the destination of students changing their mind following the negative feedback received. The data we have obtained so far do unfortunately not allow us to pursue this question further. Another important dimension to take into account for an evaluation of the effectiveness of the feedback policy is of course the possible changes that occured in drop-out rates after the first year at university, as well as in mean grades in first year examinations, or indeed in graduation rates with a three year undergraduate degree. As the policy was implemented with the aim of lowering the failure rates during the first years of university studies, it is crucial to find out whether on average students achieve better results at the end of their first year, and if those students who against the advice given to them decide to go ahead with their original plan and enroll, do indeed worse during their subsequent studies. We aim to pursue our study of the AO policy in the directions outlined above in work to be carried out in the near future. 


\section{References:}

Angrist, J.D and Pischke, J.S. (2008) Mostly Harmless Econometrics: An Empiricist's Companion, Princeton University Press.

Avery, C. (2010) The Effect of College Counseling on High-Achieving, Low-Income Students, NBER Working paper 16359.

Avery, C. and Kane, T. (2004) Student Perceptions of college opportunities: the Boston COACH program», dans Caroline Hoxby (ed.) College Choices: The Economics of Where to Go, When to Go, and How to Pay for It, Chicago: University of Chicago Press.

Azmat, G. and Iriberri, N. (2010) The Importance of Relative Performance Feed-back Information: Evidence from a Natural Experiment using High-School Students, Journal of Public Economics 94: 435-452.

Beaupère, N. and Boudesseul, G. (2009) Sortir sans diplôme de l'université - comprendre les parcours d'étudiants «décrocheurs», la Documentation Française, Paris.

Bettinger, E., Long, T. and Oreopoulos, P. (2012) The Role of Application Assistance and Information in College Decisions, The Quarterly Journal of Economics, 127(3): 1205-1242.

Goux, D., Gurgand, M. and Maurin, E. (2015) Adjusting your Dreams? High-School Plans and Dropout Behaviour, The Economic Journal, forthcoming.

Gruber, J. (1994) The Incidence of Mandated Maternity Benefits, The American Economic Review, 84(3):622-641.

Gury, N. (2007) Les sortants sans diplôme de l'Enseignement Supérieur: Temporalité de l'Abandon et Profils des Décrocheurs, L'orientation scolaire et professionnelle 36(2):137-156. 
Hahn, J., Todd, P. and Van der Klauuw (2001) Identification en Estimation of Treatment Effects with a Regression Discontinuity Design, Econometrica 69(1):201-09.

Hastings, J. S. and Weinstein, J. M. (2008) Information, school choice, and academic achievement: Evidence from two experiments, The Quarterly Journal of Economics pp. $1373-1414$.

Hastings, J.S., Neilson, C.A., Ramirez, A. and Zimmerman, S. (2010) (Un)informed College and Major Choice Evidence from Linked Survey and Administrative Data, NBER Working Paper 21330.

Lemaire, S. (2004) Que deviennent les bacheliers après le baccalauréat?, INSEE, France Portrait Social.

MSER (2015) L’État de L'Enseignement Supérieur et de la Recherche en France, Ministère de l'éducation nationale, Paris.

OCDE (2010) Regards sur l'Education 2010: Les Indicateurs de l'OCDE, OCDE, Paris.

Oreopoulos, P. and Dunn, R. (2013) Information and College Access: Evidence from a Randomized Field Experiment, Scandinavian Journal of Economics, 1(01): 3-26.

Pistolesi, N. (2016) Advising Students on Their Field of Study: Quasi-Experimental Estimates From a French University Reform, TSE Working Paper.

Stinebrickner, T.R and Stinebrickner R. (2014) Academic Performance and College Dropout: Using Longitudinal Expectations Data to Estimate a Learning Model, Journal of Labor Economics, 32(3):601-644. 


\section{Appendix: Content of the feedback sent to candidates for entry into the first year of an undergraduate degree}

The feedback given to students who express their desire to register for a degree course is sent via the Post-Bac website. There are three options: positive, neutral and negative feedback. The text these messages contain is standardised and exactly the same for any student receiving the same kind of feedback. The three messages are:

Positive feedback: "You expressed the wish to enroll in the first year of an undergraduate degree in $X$ at $Z$ University. After examination of your application form we approve of your choice. We would nonetheless like to remind you that to study for this degree requires a sound knowledge of mathematics, the capacity to handle a large workload and a taste for abstract reasoning".

Neutral feedback: "You expressed the wish to enroll in the first year of an undergraduate degree in $X$ at $Z$ University. After examination of your application form, we would like to express some reservations regarding your choice. From the grades you obtained, and from the options you chose in your last two years of high-school, it seems to us that your mastery of the skills required for this degree course is insufficient as yet. However, if you are highly motivated and ready to work extremely hard, enrollment in this degree may still be a viable option. We would like to remind you however that studying for this degree requires a sound knowledge of mathematics, the capacity to handle a large workload and a taste for abstract reasoning". 
Negative feedback: "You expressed the wish to enroll in the first year of an undergraduate degree in $X$ at $Z$ University. After examination of your application form, we have to advise you against this choice. Successfully studying for this degree requires a sound knowledge of mathematics and a taste for abstract reasoning, and your profile does not seem to correspond to these requirements. We invite you to contact your school's career counselor". 